\title{
Erratum to: Cytotoxicity of Neolignans from Magnolia obovata Fruits
}

Kyeong-Hwa Seo $\cdot$ Dae-Young Lee $\cdot$ Rak-Hun Jeong $\cdot$ Ki-Hyun Yoo

In-Sik Chung • Geum-Soog Kim • Woo-Duck Seo • Hee-Cheol Kang •

Eun-Mi Ahn • Nam-In Baek*

Published online: 30 September 2013

Erratum to: J Appl Biol Chem 56(3), 179-181

DOI http://dx.doi.org/10.3839/jabc.2013.028

Acknowledgment aremissing.

Acknowledgment shoule be listed as follows.

Acknowledgment This research was supported by a project from the Academy and Research Institute funded Korea Small and Medium Business Administration (S2091482). 